\title{
MODELOS DE INCORPORACIÓN DE INMIGRANTES: TEORÍAS Y PERSPECTIVAS*
}

\section{IMMIGRANTS' INCORPORATION MODELS: THEORIES AND PERSPECTIVES}

\author{
David Delgado Montaldo**
}

RESUMEN

En el presente artículo, se presenta una discusión teórica y un análisis de los procesos de integración —o bien de asimilación - de los inmigrantes en países o territorios de acogida. Al ser Costa Rica un país claramente receptor de población, se considera su caso en perspectiva comparada con los diversos modelos de incorporación de inmigrantes que se han desarrollado en otras latitudes, sobre todo en el continente europeo.

PALABRAS CLAVE: COSTA RICA * INMIGRACIÓN * PROCESOS DE ASIMILACIÓN * INTEGRACIÓN DE LOS INMIGRANTES * MODELOS DE INCORPORACIÓN DE INMIGRANTES

\section{ABSTRACT}

This study presents a theoretical discussion and an analysis about the immigrants' integration processes —or assimilation processes - into the hosting territories or countries. The analysis is focused on the Costa Rican case in compared perspective, considering some of the immigrants' incorporation models that have been developed in other latitudes, especially into the European continent.

KEY WORDS: COSTA RICA * MIGRATION * ASSIMILATION PROCESSES * IMMIGRANTS' INTEGRATION * IMMIGRANTS' INCORPORATION MODELS

Artículo elaborado con el apoyo del Programa Alßan, Programa de becas de alto nivel de la Unión Europea para América Latina, beca nro. E04D029723CR. Una versión ampliada de este artículo, obtuvo la máxima distinción ("Matrícula de Honor") como Diploma de Estudios Avanzados en Sociología por la Universidad de Barcelona.

** Doctorando en Sociología, Universidat de Barcelona.dd_montaldo@yahoo.com 


\section{INTRODUCCIÓN}

Costa Rica se destaca por ser un país cuyo peso de los inmigrantes internacionales es de alrededor de $10 \%$ de la población total, variando según la estimación de la inmigración indocumentada ${ }^{1}$. A diferencia de la mayoría de los países receptores de población en Norteamérica y Europa, el grueso de los inmigrantes proviene de unos cuantos países vecinos y cercanos al territorio costarricense (Nicaragua y Colombia, principalmente), cuyas prácticas culturales son semejantes y en donde el idioma oficial también es el castellano.

Lo anterior establece diferencias respecto a las dos principales naciones receptoras de población del continente: Estados Unidos y Canadá. En estos países la diversidad cultural, así como la lengua materna y los lugares de origen de los inmigrantes son muy variados, lo cual los identifica como claros modelos de "naciones multiculturales"2. Sin embargo, respecto a los procesos de integración de los inmigrantes, hay similitudes entre Costa Rica

De acuerdo con los registros en línea de la Dirección General de Migración y Extranjería de Costa Rica (DGME) [www.migración.go.cr], al día 8 de agosto de 2005 residían en el país de forma regular 285292 extranjeros; las autoridades de esta entidad estimaban que en el país residían de forma irregular alrededor de 170000 foráneos (entrevista del director de la DGME de entonces, Marco Badilla, con el periódico La Nación, 1 de marzo de 2004, pág. 4A). Para el año 2005, la estimación del número total de inmigrantes por parte del grupo de expertos en población de las Naciones Unidas fue de 440957 extranjeros (véase el sitio de internet de la ONU < http://esa.un.org/ migration/> World Migrant Stock: The 2005 Revision Population Database. La información fue consultada el 10 de junio de 2007).

La multiculturalidad entendida como un proceso que no tiene que ver con las categorizaciones de ciudadanía y nacionalidad, sino en torno a la convivencia de diversos grupos poblacionales que coexisten en un mismo territorio o nación determinada (Kymlicka, 1996). De acuerdo con Bhikhu Parekh (2005: 33): "Una sociedad multicultural consta, por definición, de diversas culturas o comunidades culturales, cada una con su propio sistema de sentido y significado y sus propios puntos de vista sobre el hombre y el mundo". y otros países receptores de población, especialmente europeos, que basan sus políticas migratorias y de integración de los inmigrantes ya sea en modelos de "asimilación" política y cultural o bien de "incorporación", especialmente cuando se trata de migración laboral.

Hay que señalar que todas las políticas de inmigración de los países se enraízan en un conjunto de ideas acerca de las fronteras nacionales y del papel del estado (Sassen, 1996 y 1999). Por ejemplo, Francia y España —al igual que lo hace Costa Rica - adoptan una política de naturalización basada en el jus soli, o lugar de nacimiento, mientras que países como Alemania y Suiza, basan las suyas en el jus sanguinis, o descendencia. Esto cobra particular interés en Costa Rica, sobre todo si se considera que, de acuerdo con las estimaciones del Centro Centroamericano de Población (CCP) de la Universidad de Costa Rica, el 18,2\% del total de nacimientos ocurridos en el país durante el año 2005 correspondieron a hijos e hijas de madres extranjeras $(15,4 \%$ de madres nicaragüenses y 2,8\% de otros países). Si bien estos niños y niñas son costarricenses por nacimiento - política de jus soli-, no necesariamente se les considerará como tales por aquéllos quienes se consideran "nativos" o "autóctonos" - sentimiento de jus sanguinis - , pues siempre serán considerados inmigrantes de segunda $y$ tercera generación.

El presente artículo, intenta ofrecer una revisión crítica a los modelos de integración de los inmigrantes en otras latitudes. El tema puede resultar interesante para el caso costarricense, pues al ser un país en el que residen cerca de 4,5 millones de habitantes, la política migratoria y la gestión de la migración internacional se vuelven una prioridad dado el peso relativo de los inmigrantes en la población total; asimismo, si bien el país sigue manteniendo un régimen de bienestar cercano al de algunas naciones europeas, aún sigue siendo claramente un país "en vías de desarrollo".

\section{CONCEPTOS Y TEORÍAS FUNDAMENTALES}

La definición del concepto de integración, referida al fenómeno de la inmigración, ha 
sido desarrollada y debatida ampliamente desde diversos campos, sean estos académicos, institucionales - sobre todo para la toma de decisiones-y desde la propia sociedad civil. Este concepto, se ha visto inmerso en una enorme confusión semiótica y ha sido objeto de paralelismos y oposiciones a otros conceptos relacionados: asimilación, incorporación, inserción, adaptación, etc. (Blanco, 2002).

Cabe señalar que, ante el actual panorama de "confusión" en torno al término integración, son pocos los autores que tratan de poner un orden relativo acerca de los procesos de integración de los inmigrantes en las sociedades receptoras, así como clarificar los modelos de convivencia que podrían ampararse en este término. Algunos comentan que la integración

... es un concepto que siempre ha ido acompañado de recelos $y$ dudas, bien por lo que conlleva de 'integrarse en' un sistema social que se critica, (...) bien porque la llamada integración se consideraba que es, en el fondo, un modelo dominante de asimilación de hecho o disfrazada (Malgesini y Jiménez, 2000: 245).

Otros autores, por su parte, se han (re)planteado la vigencia del concepto de asimilación, no en términos normativos, ni como modelo analítico de políticas públicas o prácticas informales asociadas - ya sea con la "americanización" o "europeización" de los inmigrantes en estos contextos-, sino distinguiendo su significado en dos vertientes: uno general $y$ abstracto, $y$ otro específico e instrumental (Brubaker, 2001). En el primer caso, la asimilación se refiere a un proceso, y como tal, no hace hincapié en el resultado final, sino que se trata de una cuestión de grado ("volverse semejante" o que el tratamiento sea igual para nativos e inmigrantes "en ciertos aspectos"). Desde el punto de vista instrumental, por el contrario, el énfasis está en el resultado final, siendo que la asimilación no es una cuestión de grado, sino que incluso puede referirse a una asimilación segmentada (Portes y Rumbaut, 1996).

Algunas formas de asimilación son incluso deseables: por ejemplo, la asimilación socioeconómica en aspectos como los ingresos, los tipos de trabajo de acuerdo con las cualificaciones personales y los niveles educativos; así como de tipo territorial y cultural, como su concentración espacial, en el lenguaje y en el matrimonio entre parejas de distinto origen (Waters y Jiménez, 2005). El punto central, es que se pueda estudiar la asimilación en sus distintos dominios $y$ vertientes, sin que esta tenga un enfoque asimilacionista; se puede ser agnóstico respecto a sus dominios, $y$ ambivalente o escéptico acerca de su deseabilidad (Brubaker, op. cit.).

Privadas las connotaciones asimilacionistas $^{3}$, el "concepto" de asimilación — no el "término" en sí mismo- no sólo es útil, sino que resulta casi indispensable para el análisis de los procesos de incorporación de inmigrantes en las sociedades de acogida. El mismo permite indagar los dominios y grados en que se asemejan, así como las diferencias que persisten, entre las poblaciones multigeneracionales de origen inmigrante con la población local. La asimilación no hay que entenderla como una teoría, sino como un concepto que no puede ni debe ser obviado (Brubaker, op. cit.). Más adelante, en el apartado de la asimilación y sus significados, se profundizará sobre el tema.

3 Para diferenciar la "asimilación" de un "modelo asimilacionista", debe considerarse que no se está tratando de espectativas normativas, ni de modelos analíticos, políticas públicas o prácticas informales asociadas con el uso "transitivo" del término asimilación, es decir, el de "hacerse similar", lo cual trae a la mente la idea de programas y políticas estatales que pretendían una "asimilación forzada", o al menos programas y políticas que buscaban asimilar a determinados grupos de la población en contra de su voluntad. Lo anterior es tanto moral como políticamente indeseable (piénsese por ejemplo en las campañas impositivas de los "valores americanos" entre los ciudadanos de las comunidades indígenas estadounidenses; en algunas de las prácticas homogenizadoras del republicanismo jacobino francés; o bien en la "germanización forzada" de la población polaco-parlante de los territorios fronterizos del este alemán). Lejos de esta noción, la asimilación debe comprenderse, entonces, como el análisis de la naturaleza, el grado y los dominios en que se incorpora la población de origen inmigrante en las sociedades de acogida con respecto a la población local y, por supuesto, se dirige al análisis de las desigualdades que de este proceso puedan emerger. 
Sea como fuese -integración "a la europea" o asimilación "a la americana"-, la integración de los inmigrantes en las sociedades de acogida es una meta deseable y positiva, tanto para el desarrollo de los territorios o países receptores, como para quienes han decidido emigrar de sus lugares de origen. Generalmente, este proceso se lleva a cabo al menos en cuatro instancias: el aspecto político (derechos ciudadanos), el mercado de trabajo, la escuela y la locación geográfica.

\section{LA INTEGRACIÓN COMO PARADIGMA}

El concepto de integración en las ciencias sociales no es nuevo. Desde una perspectiva teórica más cercana al funcionalismo, la integración como proceso social y humano se refiere a cómo la socialización, a través de las normas y la formación de expectativas, contribuye en la creación de la cohesión y estabilidad social; en otras palabras, en cómo se crea y se mantiene el orden social (Brochmann, 2003). La integración de los inmigrantes, desde este punto de vista, exige el aprendizaje $y$ ajuste a los valores de la sociedad de acogida; $y$ esto puede definirse, al menos parcialmente, como asimilación. Lo opuesto a esta definición de integración es la marginalización o bien la exclusión, cuando se refiere a individuos, $y$ a desintegración o anomia cuando concierne a grupos o sociedades.

El uso de este concepto es ampliamente difundido y utilizado en las políticas migratorias, $y$ alude a que la integración de los inmigrantes es una meta por alcanzar tanto por la sociedad como por los gobiernos. Tal uso, imposibilita la idea de una sociedad que pueda alcanzar una integración plena de los inmigrantes sin la intervención del estado (Favell, 2003). Sin embargo, es posible entender la integración sin considerar la estructura omnipresente del mismo: los inmigrantes pueden ser integrados dentro del mercado de trabajo, como proveedores de servicios, como inversionistas, o bien pueden integrarse a relaciones sociales y comunitarias más complejas, como las ciudades.

En el contexto político costarricense, es muy difícil concebir el concepto de integración sin considerar la estructura del estado-nación, pues el uso de este término ha servido para describir los objetivos de la política migratoria del país. Esto ha quedado plasmado en los Principios Generales de la nueva Ley de Migración de Costa Rica, ampliamente debatida y que rige desde agosto del 2006. En los apartados c) y d) del Capítulo 7 de la misma, se menciona que toda política migratoria debe contemplar:

... la integración de las personas extranjeras que permanezcan legalmente en el país, a los procesos económicos, científicos, sociales, laborales, educativos, culturales y deportivos; [además de] “... la protección de las costumbres y de la convivencia pacífica de los habitantes del país, así como el respeto a los derechos de las personas menores y de las mujeres, lo cual se reflejará en políticas restrictivas al ingreso de personas extranjeras cuando este altere los elementos y valores de convivencia (las cursivas son del autor).

La integración consiste, aquí, en imaginar las formas y estructuras institucionales nacionales que pueden unificar a una población diversa, conllevando a lo que puede hacer el estado para nacionalizar - no en términos de ciudadaníaal inmigrante y (re)configurar el estado-nación en circunstancias de crecimiento de la diversidad cultural (Favell, 2003). Según este paradigma, la concepción de integración no tiene cabida en la nueva Ley de Migración costarricense.

Debe destacarse que la construcción del estado $y$ de las instituciones sociales costarricenses, a diferencia de los países norteamericanos pero a semejanza de los países europeos, no se dieron con un sustento histórico de inmigración, pues la llegada de extranjeros que piensan residir indefinidamente en el país es un fenómeno, si se quiere, relativamente reciente. El problema radica en la adaptación - a menudo parcial- de los inmigrantes a las instituciones sociales $y$ culturales que fueron concebidas como propias de los costarricenses, en términos exclusivos y casi beligerantes (Sandoval, 2003; Jiménez, 2002).

La integración de los inmigrantes en Costa Rica se refiere, sustancialmente, a la 
incorporación de los mismos al mercado de trabajo, y ello no se da precisamente bajo las normativas tuteladas por un estado controlador, sino por las reglas y leyes que dicta el mercado. Esta forma de integración no se da de manera homogénea, más bien ocurre lo contrario. Muchos nicaragüenses y colombianos se incorporan al mercado de trabajo informal, a la economía sumergida, esa que se hace "sin papeles" y con contratos esporádicos que tanto beneficia a contratistas $y$ patrones urgidos de mano de obra no calificada $y$ barata.

El estado costarricense, así, deja de tener el control en lo referente a la migración internacional y menos aún de la integración de los inmigrantes. La política gubernamental en materia migratoria y de integración de los inmigrantes es un nubarrón disperso en el marco de políticas genéricas, tales como el acceso universal a la salud y la educación, así como a la seguridad social.

La Constitución Política de Costa Rica, por su parte, establece que la condición política de los inmigrantes, independientemente de su estatus migratorio (residente permanente, exiliado político, asilado o refugiado), les permite ser sujetos de derechos individuales y de respeto por los derechos humanos, los cuales son proporcionados por el estado. Al estar cada vez más mermadas las funciones sociales centralizadas $y$ organizadas por el estado en detrimento de las leyes del mercado, es este último, en conjunto con los procesos educativos, el que emerge como instrumento central para integrar a los inmigrantes a la sociedad costarricense.

Bajo el telón de la existencia de un régimen de bienestar, el estado costarricense tiene el propósito de velar y cuidar por todos los ciudadanos que residen en sus fronteras nacionales, incluyendo a la población inmigrante. Al igual que en los estados europeos, un punto crucial en este aspecto es cuántos de los inmigrantes, $y$ en qué forma, se integran en los sistemas productivos nacionales (Brochmann, op. cit.).

La organización del estado-nación costarricense ha implicado un nuevo estatus para los no ciudadanos, quienes han podido demandar sus derechos basados en su residencia en el país más que en su ciudadanía. En el caso de algunas naciones europeas, esta situación creó nuevos alcances para la acción entre los miembros de las minorías (entre ellos los inmigrantes), quienes no fueron incorporados a las sociedades de acogida bajo el manto de los paradigmas de la integración o de la asimilación (Brochmann, op. cit.).

Así las cosas, se sigue discutiendo sobre las vías o modelos más idóneos respecto de la integración de los inmigrantes, en donde los enfoques más conocidos se circunscriben a la distinción clásica entre las nociones "étnica" y "cívica" de la nación. En tal sentido, para tener más argumentos evaluativos sobre qué tipos de estados-naciones son más idóneos en los procesos de integración de los inmigrantes, es necesario mirar algunos indicadores, entre ellos: el grado de segregación social en las sociedades de acogida, el éxito y desempeño que tienen las instituciones educativas, la incorporación a los mercados de trabajo, las diferencias y resistencias culturales, la persistencia de actitudes racistas, $y$ la movilidad social de los grupos o poblaciones inmigrantes (Favell, 2003).

\section{MODELOS DE INCORPORACIÓN DE INMIGRANTES EN EUROPA}

La integración de los inmigrantes se puede basar, fundamentalmente, en dos cuestiones: la primera, es la tipología de políticas migratorias - cuando existen-con que se encuentran en las sociedades de acogida, respecto a los recursos institucionales de las mismas y los modelos de legitimación. La segun$\mathrm{da}$, es la pertenencia a una red de relaciones sociales -entendida como forma de capital social - que permitan, por un lado, el desplazamiento del país de origen al de destino y, por el otro, que ofrezcan formas de acoplamiento que no se circunscriban únicamente en la obtención de empleo, sino que además pueden otorgar elementos de reafirmación de sus identidades en los territorios de acogida.

Respecto al primer punto, una de las tipologías de modelos de integración o de incorporación de los inmigrantes, sobre todo en las sociedades post-industriales, es la elaborada por Yasemin Nuhoğlu Soysal, quien examinó los casos de algunos países europeos. La autora 
describe al menos cuatro modelos de incorporación de los inmigrantes a una comunidad política, estado o nación, ya fuera en forma colectiva o individual (Soysal, 1994).

El primero de ellos es el modelo de incorporación corporativista, que es propio de países como Suecia y Holanda, donde la población inmigrante se define por su identidad colectiva. Como grupos colectivos, su relación vis-à-vis con el estado es clara y se asemeja a la de cualquier grupo social corporativizado (como por ejemplo los sindicatos y las asociaciones gremiales).

En estos países se generan políticas instrumentalizadas para la incorporación de inmigrantes, pero a su vez, en su discurso político se refieren a ellos abiertamente como "minorías étnicas". Esta situación conlleva a que las mismas políticas que promueven la integración de los inmigrantes, refuercen la "diferencia" en la categorización de etnicidad en el imaginario social.

El segundo modelo de incorporación de inmigrantes al que la autora hace referencia es el individualista, también denominado liberal. Tanto Suiza como Inglaterra son ejemplos claros de este tipo de modelo. En ambos países, los inmigrantes no son definidos por su afiliación o corporativización de grupo, sino como individuos, cuya posición en la sociedad de acogida se determina por su participación en el mercado de trabajo.

En Suiza, la regulación de los flujos migratorios está muy bien instrumentalizada políticamente y constituye el principal aliado de la política federal migratoria, la cual controla el tamaño de la población extranjera en concordancia con las demandas del mercado laboral, siempre bajo los tres principios de la política gubernamental: la estabilización y equilibrio (regulación numérica) de la población inmigrante, el mejoramiento de la estructura del mercado de trabajo, $y$ la integración. Esta denota un proceso individual, y significa que el extranjero debe hallar por sí mismo una situación en la que pueda realizarse y tener éxito en su vida personal $y$ profesional.

En Inglaterra, por su parte, la política migratoria se basa en el concepto de "igualdad racial", esto debido a su pasado colonialista y a que el flujo de inmigrantes procedía mayoritariamente de sus ex-colonias y de los países de la
Commonwealth (Favell, 2001). El objetivo de la política oficial de inmigración británica es la de facilitar la integración, esforzándose en conseguir la igualdad de oportunidades y promoviendo a su vez las "buenas relaciones entre razas", con una serie de acciones legales que prohíben la discriminación de las minorías étnicas en cualquier ámbito de la vida social y económica del país.

El tercer modelo de incorporación de los inmigrantes es el estatista, cuyo ejemplo más notorio es el de Francia. Si bien el estado francés considera a los inmigrantes como individuos, lo hace desde una perspectiva mucho más centralizada — desde el estado- para su integración respecto del modelo liberal-individualista. Al contrario de Inglaterra y Suiza, el estado francés participa y tiene más responsabilidades hacia los inmigrantes para mejorar su bienestar, pues muchas de las funciones sociales están centralizadas y organizadas por el propio estado.

En Francia, el concepto de integración adquiere un significado estato-céntrico, pues asume a los individuos (entre ellos los inmigrantes) en un plano igualitario de los derechos que son proporcionados por el estado. Así, se desanima la formulación de políticas o acciones especiales, al igual que la aparición de organismos de intermediación vinculados con los grupos de inmigrantes (Favell, 2001).

La noción de integración por parte del estado francés favorece el acceso de los inmigrantes - como individuos y no como grupos específicos- a los servicios e instituciones formales de la sociedad, entre ellos la sanidad, la educación e incluso, las relativas facilidades para la naturalización en comparación con otros países europeos; al menos así fue hasta mediados de la década de los setenta, cuando la inmigración provenía mayoritariamente de países de la Unión Europea ${ }^{4}$. De hecho, las

Javier Moreno (2004: 42) apunta que “... el hecho que los sistemas de protección social franceses se estructurasen en gran medida con base a la participación activa y legal en el mercado de trabajo implicó que (...) el tema de la utilización 'abusiva' de los esquemas de protección social de los extranjeros raramente ocupó un papel predominante en la agenda política francesa”, [o al menos así fue 
minorías religiosas o étnicas no son reconocidas legalmente como categorías, contrastando categóricamente con el caso del modelo de incorporación corporativista de Suecia y Holanda.

La política de inmigración francesa no tiene que ver con categorías colectivas. Al contrario, el mercado y los procesos educativos son los principales instrumentos bajo los cuales los inmigrantes se incorporan plenamente, si bien desde un ámbito individual, con la intervención directa del estado en este proceso. Existen políticas del estado dirigidas a la población inmigrante, sobre todo para dotarles de habilidades y competencias específicas para tener acceso a las instituciones de la sociedad francesa en condiciones de igualdad con la población nativa o autóctona ${ }^{5}$.

hasta la aparición del grupo de extrema derecha Frente Nacional, encabezado por Jean Marie Le Pen. El mismo autor continúa:] “... en términos welzerianos, la situación francesa sería equiparable a un equilibrio de comunidad cuasi-cerrada (derechos sociales en gran medida circunscritos a la participación en el mercado de trabajo), y control de fronteras relativamente laxo (al menos en comparación con el caso británico)".

Los actos de violencia y disturbios acaecidos en los barrios periféricos parisinos a finales de octubre e inicios de noviembre del 2005 , obedecen más a una mala praxis de las políticas públicas del modelo de bienestar francés que a un fracaso del modelo de integración de los inmigrantes - sobre todo jóvenes y de segunda generación-; esta crisis, afecta a la población francesa en general y no sólo a la población de origen inmigrante. Como bien lo señalaba Michel Wieviorka (en el periódico La Vanguardia de España, 8/11/2005): “... la crisis de los barrios periféricos es ante todo social: pobreza, exclusión, precariedad, paro masivo, sobre todo entre los jóvenes, $y$, como ocurre con una parte importante de unas poblaciones procedentes de la inmigración, racismo y discriminación. A continuación, es institucional en la medida en que fallan las instituciones que deberían encarnar de forma concreta la idea republicana (la libertad, igualdad, fraternidad); ya se trate, por ejemplo, de la policía, cuyos controles motivados por el aspecto físico y cuyo racismo concuerdan poco con el principio de libertad, o de la escuela pública, que refuerza las desigualdades sociales en lugar de garantizar la igualdad. La crisis de los barrios periféricos es también cultural en la medida en que lo que constituía el único horizonte identitario, la nación, se ve contestado por toda clase de identidades colectivas que piden reconocimiento
Un último caso que señala Yasemin Soysal es el denominado modelo mixto, que caracteriza a la nación alemana. Este país presenta aspectos tanto del modelo de incorporación estatista como del corporativista. A pesar de que la política oficial alemana respecto a los inmigrantes es clara en señalar que los mismos no deben ser considerados como minorías étnicas, tampoco provee los insumos necesarios para la participación de los inmigrantes como grupos colectivos en la sociedad. En términos organizacionales, se desarrolla un proceso de incorporación de los inmigrantes en forma centralizada y corporativizada desde el estado, en concordancia con otras estructuras institucionales alemanas.

La definición que el gobierno alemán le otorga al concepto de integración tampoco está dirigida a grupos colectivos. El instrumento más importante para la integración en la política alemana es la capacitación vocacional y la misma educación, sobre todo para los inmigrantes de segunda generación. La misma les permite ajustarse tanto a las categorías ocupacionales como al fortalecimiento de su posición en el mercado de trabajo; a su vez, esto representa el principal vehículo de movilidad económica y social para la población inmigrante (IOM, 2003).

Si se considera que en la mayoría de los casos expuestos las políticas de integración de los inmigrantes se desarrollaron como una reacción al modelo "asimilacionista", basado en un modelo cultural-pluralista —al menos en el plano ideológico-, se puede decir que la integración responde a un intento por lograr la coexistencia pacífica entre los diferentes grupos étnicos, $y$ de ahí que haya tomado fuerza en los últimos años el concepto de multiculturalismo, como esa forma "positiva" de percibir las diferencias étnicas (Brochmann, op. cit.). De nuevo, se cae en una especie de antagonismo, pues la población nativa puede percibir y creer que realmente existe una "cultura nacional" tan propia de su estado-nación como legítima,

en el espacio público(...). Por último, se trata de una crisis política, porque ya no existen en esos barrios populares las instancias que aseguraban la mediación entre las demandas de los habitantes y el sistema político y el Estado". 
$y$ que por supuesto se encuentra en un estadio superior con respecto a esas minorías étnicas, o bien de la población extranjera.

La exposición de modelos de incorporación bajo la estructura política y territorial de diversos estados-naciones - muy propio de los países europeos- permite la comparación con el caso costarricense, pues la configuración del estado de este país centroamericano se dio a partir del modelo republicano francés (libertad, igualdad $y$ fraternidad). Sin embargo, con base en las tipologías expuestas, no es posible encasillar a Costa Rica con sólo uno de los modelos específicos de incorporación de inmigrantes en los países europeos señalados, pues toma elementos que se encuentran, sobre todo, en los modelos estatista $y$ liberal.

\section{LA ASIMILACIÓN Y SUS SIGNIFICADOS}

Rogers Brubaker mencionó que, mientras el término asimilación había regresado, el concepto había sido transformado. Entre los principales elementos para que este autor aseverara su transformación, se encuentran las siguientes (Brubaker, op. cit.):

a) Un cambio en la comprensión del significado de la asimilación, anteriormente pensado como un proceso de absorción completa, a centrarse en los procesos de asimilación parcial respecto a algunos aspectos de la población nativa.

b) Una tendencia a comprender la asimilación como un proceso social, entendiéndose en un nivel agregado, más que como un proceso que ocurre - consciente o inconscientemente- a un nivel individual.

c) Cambios inter-generacionales importantes (sobre todo en el aprendizaje de la lengua $y$ otros dominios, en el caso de los Estados Unidos y Europa), que permiten que halla cambios en la población tanto inmigrante como nativa.

d) Pasar de creer en formas homogéneas de ciudadanía e identidades, a pensar en que existen en realidad unidades heterogéneas, que enriquecen los estados y naciones, ahora bajo el manto de las sociedades multiculturales. e) La realización de investigaciones más enfocadas a la asimilación en los aspectos socioeconómicos, que en la asimilación cultural de los inmigrantes. Así, la asimilación no es entendida en términos de "diferencia", sino en términos de "segregación", "guetización" y "marginalización".

f) El cambio de la perspectiva monodimensional de la cuestión — ¿cuán asimilados son?- hacia una perspectiva multidimensional - ¿asimilación en qué aspectos, en qué periodo o ciclo de vida, en cuál población?

Mientras que la aculturación es el primer paso del proceso de adaptación, y se define por las distintas formas de aprendizaje de los valores, la cultura y hasta algunos códigos de la sociedad de acogida (entre ellos el lenguaje, cuando es el caso), el estadio final de este proceso puede denominarse asimilación. En ocasiones, se ha visto que los resultados de este proceso de asimilación se vuelven segmentados, como consecuencia de la interacción entre el contexto social en el cual los inmigrantes de segunda generación crecen y las pautas de aculturación en el que se desenvuelven sus padres (Portes y Rumbaut, op. cit.).

De acuerdo con algunos autores (Alba $y$ Nee, 2003), una definición viable de la asimilación debe reconocer que la etnicidad es esencialmente una frontera social, una distinción que los individuos hacen acorde con sus acciones y sus formas de pensar hacia los "otros"; asimismo, que esta distinción usualmente es enmarcada en algunas diferencias sociales $y$ culturales entre los distintos grupos que le dan a esas fronteras étnicas significaciones concretas (estos grupos pueden pensar, por ejemplo: -“Ellos no son como nosotros porque..."); y por último que la asimilación, como un concepto móvil, puede ocurrir a través de los cambios que tienen lugar en los grupos de ambos lados de las fronteras nacionales ${ }^{6}$. En consecuencia, la asimilación de los inmigrantes puede definirse como la declinación de una distinción étnica $y$ de sus diferencias socioculturales.

$6 \quad$ Véanse los aportes en esta materia de algunos autores como Alejandro Portes (1996 y 1997) y Yerko Castro Neira (2005) en torno al concepto de "comunidades transnacionales". 
De esta manera, el origen étnico y la misma nacionalidad de los individuos se vuelven cada vez menos relevantes en su relación con los miembros de los otros grupos poblacionales, llámense estos nativos (típicamente, pero no necesariamente, el grupo mayoritario), $y$ en donde los individuos de ambos lados de las fronteras nacionales o territoriales se ven a sí mismos más y más semejantes, en términos de otros factores estructurales como, por ejemplo, la clase social (vista en indicadores como el tipo de trabajo que desempeñan, sus relaciones familiares, las escuelas a las que acuden, entre otros). Esta definición, facilita la asimilación de los inmigrantes en cuanto que, como miembros de un grupo minoritario, no detectan una ruptura entre la participación en las instituciones de la sociedad de acogida y sus prácticas sociales y culturales (Alba y Nee, op. cit.).

En términos concretos, la asimilación de los inmigrantes es siempre un dominio específico y relativo a una población particular, en donde la instancia normativa que se puede tomar dependerá de este dominio y población de referencia. Así, hoy en día este concepto ha dejado de ser unidireccional, $y$ tanto las poblaciones de nativos como de inmigrantes se ajustan a esta realidad, la cual está marcada por el fenómeno de la incorporación de nuevos grupos en las sociedades de acogida como producto de la migración internacional (Brubaker, op. cit.).

Richard Alba y Victor Nee estipulan que los sujetos actúan en función de los marcos cognitivos que los mismos se han formado, basados en sus creencias culturales (costumbres, normas sociales, leyes, ideología, religión), $y$ en las que moldean a su vez las percepciones de sus propios intereses. De esta forma, ven la racionalidad como una frontera contextual $y$ contingente, en contraste a las presunciones de la racionalidad de la corriente de la economía neoclásica, donde los individuos maximizan sus utilidades en función de sus conocimientos $y$ subestimando su capacidad cognitiva (Alba $y$ Nee, op. cit.).

Todo lo anterior, conduce a la necesidad de explicar porqué los inmigrantes -y sus descendientes - buscan "asimilarse" en los territorios de acogida, o bien porqué los mismos son frecuentemente "asimilados" involuntariamente en su búsqueda de otros objetivos. Contrario a muchas de las corrientes teóricas recientes sobre la asimilación, esta teoría no asume que la misma es inevitable $y$ tan siquiera irreversible, sino que es el resultado de un contingente de acciones provenientes del efecto acumulativo de opciones individuales, así como de la acción colectiva de estos grupos, y que ocurre en diversas formas dentro, entre y a través de los mismos en su relación con la población nativa (Alba y Nee, op. cit.).

\section{CONSIDERACIONES (¿PERSPECTIVAS?) PARA EL CASO COSTARRICENSE}

Entre los muchos mitos en que se encuadran las formas de ser, pensar y sentir de los costarricenses - además de su supuesta homogeneidad cultural y racial-, se encuentran su vocación democrática, de diálogo y de paz, las metáforas de la nacionalidad (basada en el jus solis pero "asimilada" como jus sanguinis), el discurso liberal de blanqueamiento y el de sus fronteras étnicas, delimitadas entre el Valle Central y el resto del país (Jiménez, 2002). En tal sentido, diversos estudios señalan que la población inmigrante residente en Costa Rica, sobre todo la de origen nicaragüense y colombiana, representan en el imaginario social costarricense todo lo contrario (López et al., 2006).

A los nicaragüenses se les ve como peligrosos, violentos y amenazantes, $y$ esto es debido en buena medida por el realce $y$ exacerbación de estas manifestaciones en los medios de comunicación nacionales, que tienden a mostrar estas imágenes negativas de la población (Sandoval, 2003). Por su parte, los colombianos deben cargar con el estereotipo de venir de un país "en eterno conflicto" entre el gobierno, paramilitares, guerrilleros y narcotraficantes. Se dice que los colombianos vienen de una cultura del miedo y la violencia, ergo, también son peligrosos, violentos $y$ amenazantes.

Si bien Costa Rica es un país diverso cultural y étnicamente, calificativo que no ha sido heredado únicamente del fenómeno de la 
inmigración ${ }^{7}$, también es cierto que tanto en el ámbito de la conformación de identidades nacionales como en el del accionar político del estado (en materia tanto legal como económica), el mismo crea desigualdades y procesos de exclusión hacia sus ciudadanos (incluyendo los de origen inmigrante). En este ámbito, uno de los sectores de la población que se ha visto más afectada es precisamente la de los inmigrantes que residen en el territorio costarricense, en especial aquellos que se encuentran indocumentados.

Esta situación no tiene que ver con las categorizaciones de ciudadanía y nacionalidad, sino en torno a la convivencia de diversos grupos poblacionales que coexisten en un mismo territorio. Costa Rica se destaca por ser un país que, claramente, segrega y excluye a estas poblaciones de acuerdo con su origen (el afrocaribeño, el indígena, el nicaragüense, el colombiano) y su condición sociopolítica (el extranjero, el inmigrante, el indocumentado).

Como se señaló, la conformación del estado costarricense no se dio a partir de la diversidad cultural emanada de la presencia de personas y familias inmigrantes, esto es, si se quiere, un fenómeno reciente; lo que sí es importante destacar es que este fenómeno ha venido a reconfigurar el escenario nacional y a delinear nuevas políticas de gestión y de control (reforzamiento policial y represivo sobre todo en las fronteras nacionales) de la inmigración internacional. La política de migración está forjándose desde distintas esferas, que van desde los procesos de globalización económica a la asunción de los acuerdos internacionales en materia de derechos humanos, lo cual implica que todos los residentes del país, sean ciudadanos nacionales o no, pueden invocar sus derechos humanos.

Lo anterior reconfigura las bases de legitimidad del estado de derecho costarricense, así como la noción de nacionalidad. Como lo menciona Saskia Sassen refiriéndose al papel del estado en un mundo globalizado, se ha dado un proceso en el que el mismo pasó de basarse

$7 \quad$ El claro ejemplo de ello es el Caribe costarricense, donde reside la mayoría de la población afro caribeña del país y que se diferencia culturalmente del resto del territorio nacional. exclusivamente en la soberanía del pueblo y del derecho a la autodeterminación, a basarse en los derechos de los individuos, independientemente de su nacionalidad (Sassen, 1996).

Contrario a lo que acontece sobre todo en algunos países de la Unión Europea, en donde se les garantiza a los extranjeros plenos derechos civiles - ya sea constitucional o estatutariamente-, en Costa Rica a pesar de que estos derechos tienen rigor constitucional, en el acontecer cotidiano los inmigrantes se encuentran con una diversidad de obstáculos tanto institucionales como de discriminación social y de estigmatización hacia ellos que dificultan que los mismos puedan "sentirse" como nacionales, así como integrarse plenamente a la vida política, social y cultural costarricense. El hecho que el inmigrante ya posea la nacionalidad costarricense no implica la igualdad de derechos respecto a la población nativa, incluso, esto es válido igualmente para los hijos de inmigrantes, quienes a pesar de tener la nacionalidad por haber nacido en suelo costarricense, siempre cargarán con el estigma de "extranjero" heredado de sus padres.

Así, los procesos de integración de los inmigrantes en Costa Rica pasan por encima de las leyes y políticas migratorias -ineficaces en todo caso- emanadas desde el estado, $y$ de poco vale el hecho de adquirir la nacionalidad costarricense: extranjero e hijo de extranjero siempre serán "extranjeros", así los hijos de los inmigrantes hayan nacido en territorio costarricense y ostenten la nacionalidad del país adoptivo de sus padres. Como mecanismos de defensa, muchos inmigrantes sufren un proceso —en unos de forma más acelerada — de pérdida u ocultación de su propia identidad.

Como se mencionó en apartados anteriores, los mecanismos de integración de los inmigrantes no están estipulados por leyes emanadas del estado, pues este les atribuye una condición individual semejante a la de los ciudadanos nativos, en cuanto a igualdad de derechos $y$ oportunidades (acceso a la salud $y$ la educación, por ejemplo). La integración de la mayoría de los inmigrantes pasa por el filtro de su incorporación al mercado de trabajo, $y$ frente a un estado más liberalizador que centralista en esta materia - en parte por los procesos de 
globalización e internacionalización de la economía-, poco importa su condición migratoria bajo la cual permanecen en el país.

Sea como fuese, la legislación de extranjería en Costa Rica es muy pobre en lo referente a la integración de los inmigrantes. Prevalece más bien una política de "selectividad" de los flujos de migración, sobre todo la de naturaleza económica. El Artículo 6 de la nueva Ley de Migración, establece que la formulación de la política migratoria debe estar orientada, principalmente, a lo siguiente (las cursivas son del autor):

a) Seleccionar los flujos migratorios, con el objeto de incrementar la inversión de capital extranjero y fortalecer el conocimiento científico, tecnológico, cultural y profesional, en las áreas que para el Estado se definan como prioritarias.

b) Facilitar el retorno de las personas nacionales residentes en el exterior que deseen regresar al país y, en particular, promover el retorno de quienes posean altas cualificaciones profesionales o técnicas, cuando su reinserción en el país los posibilite, según los requerimientos del mercado de trabajo $y$ lo aconsejen las razones científicas, tecnológicas, económicas, educacionales o sociales.

c) Controlar el ingreso de personas extranjeras al país, su permanencia en él, así como su egreso, en concordancia con la seguridad pública, y con los mejores intereses para el país.

d) Orientar la inmigración a las zonas cuyo desarrollo se considere prioritario, hacia actividades y ramas económicas que para el Estado resulte de interés favorecer.

Se puede apreciar una clara relación entre las condiciones políticas por un lado, $y$ las socioeconómicas por el otro, que ofrece la particular configuración de las leyes del estado costarricense en materia migratoria. El primero de los componentes (el político) muestra una serie de cierres para impedir la "inmigración desmedida" - utilizando el lenguaje oficial-, sin embargo, la inmigración se sigue dando, aunque según los últimos informes, en menor escala. El segundo componente (el socioeconómico) pareciese, por el contrario, ofrece ventajas comparativas respecto a los países o territorios de origen de los inmigrantes, sobre todo si se considera, de una parte, la dinámica de oferta $y$ demanda de empleos en determinadas actividades y zonas del país y, por otra, la existencia de una densa red de relaciones personales con que cuentan los inmigrantes.

Sin embargo, al parecer últimamente Costa Rica ha dejado de ser tan atractiva en términos de estas ventajas con respecto a otros países de la región, como El Salvador y Panamá, que han experimentado un incremento en la llegada de mano de obra inmigrante (sobre todo de origen nicaragüense $y$ colombiana, respectivamente) para las labores agrícolas y de exportación. Esta situación no ha calado muy bien entre muchos productores locales, urgidos de mano de obra nicaragüense para sus cosechas, quienes ven con malos ojos este fenómeno.

Con todo lo anterior, es más factible referirse a los términos en que ocurre la "asimilación" de los inmigrantes en la sociedad y cultura costarricense, que no es algo impuesto desde la sociedad de acogida, pues comparten más cosas en común que diferencias tanto lingüísticas como culturales. La asimilación a la que se hace referencia se circunscribe sobre todo en la sociedad receptora; $y$ en tal sentido, la educación por el respeto y tolerancia a los derechos humanos de nativos e inmigrantes por un lado, $y$ las redes sociales con que cuentan estos últimos en los territorios de destino por el otro, juegan un papel trascendental.

El hecho de que la lengua materna de la mayoría de los inmigrantes sea el castellano, al igual de que practiquen el mismo credo religioso $y$ de que tengan gustos y prácticas culturales (sobre todo culinarias $y$ deportivas) similares a las de la población nativa, marca diferencias respecto a los procesos de integración de los inmigrantes que ocurren en los países norteamericanos y europeos. Sin embargo, las similitudes culturales y lingüísticas de los nativos con los grupos mayoritarios de inmigrantes, no determinan en lo absoluto el sentimiento de "pertenencia" a una sociedad específica (Crowley, 1999).

Es válido señalar, entonces, que en Costa Rica no existe una separación clara entre las desigualdades reales (inequidades sociales como 
la pobreza y el acceso o derecho a los servicios sociales por parte de nativos e inmigrantes) y lo que las desigualdades significan en términos de la construcción de imaginario social: nosotros los blancos y pacíficos, ustedes los oscuros y amenazantes, ellos los inversores y turistas.

\section{REFERENCIAS BIBLIOGRÁFICAS}

Alba, Richard y Victor Nee. Remaking the American Mainstream. Assimilation and Contemporary Immigration. Cambridge, MA: Harvard University Press, 2003.

Asamblea Legislativa de la República de Costa Rica. "Ley de Migración y Extranjería. Informe sobre la redacción final del texto aprobado en primer debate", 9 de junio de 2005. Departamento de Comisiones Legislativas. Expediente 14 269. San José: Comisión Permanente Especial de Redacción.

Blanco, Cristina. "Los inmigrantes y su integración. Apuntes en torno a una creciente nebulosa de conceptos, modelos y políticas”. Francisco García Castaño y Carolina Muriel López (editores). La inmigración en España: contextos y alternativas II. Granada. Laboratorio de Estudios Interculturales, 2002: 71-82.

Brochmann, Grete. "Citizens of Multicultural States: Power and Legitimacy". Grete Brochmann (editora). The Multicultural Challenge. Comparative Social Research 22. Oxford. JAI-Elsevier, 2003: 1-11.

Brubaker, Rogers. "The return of assimilation? Changing perspectives on immigration and its sequels in France, Germany and the United States". Ethnic and Racial Studies 24. 4. 2001: 531-548.

Castro Neira, Yerko. "Teoría transnacional: revisitando la comunidad de los antropólogos”. Política y Cultura 23. 2005: 181-194.
Crowley, John. "The politics of belonging: some theoretical considerations". Andrew Geddes y Adrian Favell (editores). The Politics of Belonging: Migrants and Minorities in Contemporary Europe. Contemporary Trends in European Social Sciences. Aldershot. Ashgate Publishing Ltd, 1999: 15-41.

Favell, Adrian. "Integration Nations: The Nation-State and Research on Immigrants in Western Europe". Grete Brochmann (editora). The Multicultural Challenge. Comparative Social Research 22. Oxford. JAIElsevier, 2003: 13-42.

(1998). Philosophies of Integration. Immigration and the Idea of Citizenship in France and Britain. Segunda edición. Nueva York: Palgrave Publishers Ltd, 2001.

International Organization for Migration. World Migration 2003. Managing Migration: Challenges and Responses for People on the Move. Ginebra: IOM, 2003.

Jiménez Matarrita, Alexander. El imposible país de los filósofos. El Discurso filosófico y la invención de Costa Rica. San José: Ediciones Perro Azul, 2002.

Kymlicka, Hill. Ciudadanía multicultural. Una teoría liberal de los derechos de las minorías. Primera edición en castellano. Barcelona: Paidos, 1996.

López Ruiz, Luis A. et ál. "Identidades nacionales, integración y ciudadanía: percepciones hacia la inmigración". Serie Pulso Nacional 47. Heredia: IDESPOUniversidad Nacional Autónoma, 2006.

Malgesini, Graciela y Carlos Jiménez. Guía de conceptos sobre migraciones, racismo $e$ interculturalidad. Madrid: Catarata, 2000 . 
Moreno Fuentes, Francisco Javier. Politicas sanitarias hacia las poblaciones de origen inmigrante en Europa. Madrid: Consejo Económico y Social, 2004.

Parekh, Bhikhu. Repensando el multiculturalismo: diversidad cultural y teoría politica. Pimera edición en castellano.Madrid: Ediciones Istmo, SA, 2005.

Portes, Alejandro y Rubén G. Rumbaut. (1990). Immigrant America: A Portrait. Segunda edición. Berkeley, CA: University of California Press, 1996.

Portes, Alejandro. "Immigration Theory for a New Century: Some Problems and Opportunities". International Migration Review 31. 4. 1997: 799-825.

"Transnational Communities: Their Emergence and Significance in the Contemporary World System". R. P. Korzeniewicz y W. C. Smith (editores). Latin America in the World Economy. Westport, CN. Greenwood Press, 1996: 151-168.
Sandoval García, Carlos. Otros amenazantes. Los nicaragüenses y la formación de identidades nacionales en Costa Rica. Primera reimpresión. San José: Editorial de la Universidad de Costa Rica, 2003.

Sassen, Saskia. Guests and Aliens. Nueva York: New Press, 1999.

Losing Control? Sovereignty in an Age of Globalization. Nueva York: Columbia University Press, 1996.

Soysal, Yasemin. Limits of Citizenship. Migrants and Postnational Membership in Europe. Chicago: Chicago University Press, 1994.

Waters, Mary C. y Tomás R. Jiménez. "Assessing Immigrant Assimilation: New Empirical and Theoretical Challenges". Annual Review of Sociology 31. 2005: 105-125.

Wieviorka, Michel. "Fracaso del modelo de integración”. Opinión, La Vanguardia. 8 de noviembre 2005: 23. 
